\title{
Influence of Adding Encapsulated Phase Change Materials in Aerial Lime
} based Mortars

\author{
Sandra Cunha, a , José B. Aguiar ${ }^{1, b}$ Victor M. Ferreira ${ }^{2, c}$ and António Tadeu ${ }^{3, d}$ \\ ${ }^{1}$ University of Minho, Campus de Azurém, 4800-058 Guimarães, Portugal \\ ${ }^{2}$ University of Aveiro, Campus Universitário de Santiago, 3810-193 Aveiro, Portugal \\ ${ }^{3}$ University of Coimbra, Rua Luís Reis Santos - Pólo II, 3030-788 Coimbra, Portugal \\ asandracunha86@gmail.com, baguiar@civil.uminho.pt, cvictorf@ua.pt, 'tadeu@dec.uc.pt
}

Keywords: Phase Change Materials (PCM); Polymer Microcapsules; Thermal Mortars; Workability; Mechanical Behaviour; Shrinkage

\begin{abstract}
Increasingly in a society with a high growth rate and standards of comfort, the need to minimize the currently high energy consumption by taking advantage of renewable energy sources arises. The mortars with incorporation of phase change materials (PCM) have the ability to regulate the temperature inside buildings, contributing for an increase in the level of thermal comfort and reduction of the use of heating, ventilation and air conditioning (HVAC) equipment, using only the energy supplied by the sun. However, the incorporation of PCM in mortars modifies some of its characteristics. Therefore, the main objective of this study was the characterization of mortars doped with two different phase change materials. Specific properties of different PCM, such as particle size, shape and enthalpy were studied, as well as the properties of the fresh and hardened state of these mortars. Nine different compositions were developed which were initially doped with microcapsules of PCM A and subsequently doped with microcapsules of PCMB. It was possible to observe that the incorporation of phase change materials in mortars causes differences in properties such as compressive strength, flexural strength and shrinkage. After the study of the behaviour of these mortars with the incorporation of two different phase change materials, it was possible to select the composition with a better compromise between its aesthetic appearance, physical and mechanical characteristics.
\end{abstract}

\section{Introduction}

Presently, it is possible to verify the increase regarding the concerns with environmental and living conditions quality. In fact, a huge concern related to the high energy consumption in buildings and the negative impacts for the environment associated with them has emerged. Thus, there is an urgent need to study and develop new constructive solutions that allows the minimization of this problem. The largest part of the energy consumption in residential sector is associated with heating and cooling. Therefore, it becomes imperative to obtain a constructive solution which minimizes these consumptions, improving the level of comfort inside buildings, without damaging the environment. Furthermore, it is important to consider constructive solutions with renewable energy resources providing an improvement in the quality of the buildings, especially in the comfort level of the occupants.

The incorporation of Phase Change Materials in mortars for the internal coating appears as a possible solution in an attempt to solve, or at least minimize, the massive energetic consumption related with buildings. The use of this material allows the regulation of temperature inside buildings through latent heat thermal energy storage, using only solar energy as a resource. Therefore, the incorporation of PCM in interior mortars, with the aim to reduce energetic consumption, allows us to delineate new ways to obtain a construction with a higher value of sustainability. For that reason, it is important that the construction industry is innovative and accepts new solutions for solving problems with several years. 
The phase change materials have been successfully applied in the construction industry [1], however not too much is known about the performance of construction materials such as mortar coating, doped with such materials. The main objective of this work was the production and study of a mixed lime-gypsum mortar with incorporation of two different PCM polymeric microcapsules, available in the market, intending to study the mechanical behavior of the developed mortars, as well as the shrinkage caused by the inclusion of PCM polymeric microcapsules.

\section{Phase Change Materials}

It is known that all materials interact with the environment. However most of them lack the capability to alter their own properties according to the environment characteristics in which they are applied. Phase change materials possess the capability to alter its own state as function of the environmental temperature. In other words, when the surrounding environmental temperature of PCM increases until the materials fusion point, the material suffers a change from a solid state to a liquid state, absorbing and storing the heat energy from the environment. On the other hand, as the temperature decreases until the PCM solidification point, the material alters from the liquid state to solid state, releasing the previously storage energy to the environment.

For the correct use of the PCM, it must be encapsulated, otherwise during the liquid phase there is a possibility that it moves from the original area of application. The microencapsulation of PCM consists on covering the material particles, with a material, usually a polymer, commonly known capsule, with dimensions between $1 \mu \mathrm{m}$ to $60 \mu \mathrm{m}$. The polymer used could be polymethylmethacrylate, polyurea, polyurethane or polivinilacetano and should respond at some demands of operation as high heat transfer.

\section{Materials, compositions and fabrication}

Materials. In this investigation were used two different types of PCM microcapsules, designated as A and B. Both samples were used in powder form, that is, completely dry, although there is also the possibility of obtaining the same material in emulsion. In this study we decided use the dry PCM in order to facilitate their incorporation in pre-mixed mortars.

The PCM microcapsules tests were performed, comparing the PCM provided by two different producers. The microcapsules $\mathrm{A}$ are constituted by a wall in polymethylmethacrylate and a core in paraffin, with temperature transition of about $23{ }^{\circ} \mathrm{C}$ and enthalpy of $110 \mathrm{~kJ} / \mathrm{kg}$. The microcapsules B are composed of a wall in melamine-formaldehyde and a core in paraffin, with temperature transition of about $24{ }^{\circ} \mathrm{C}$ and enthalpy of $147.9 \mathrm{~kJ} / \mathrm{kg}$. The tests conducted using the high resolution scanning electron microscope indicate that the polymer present in the microcapsules A is rougher (Fig.1) compared to the polymer used in the microcapsules B (Fig. 2) that present a more regular texture. With the purpose of obtain more information related to the dimensions of PCM microcapsules studied, granulometry tests were performed, using a laser particle size analyzer. It was possible to observe that the microcapsules A are agglomerated, having a greater dimension when observed under the electron microscope. However, the agitation that the sample suffer during this test, allows the dispersion of agglomerated microcapsules. In this way was possible concluded that the microcapsules A have an average particle size of $15.4 \mu \mathrm{m}$ and the microcapsules B an average particle size of 25.22 $\mu \mathrm{m}$.

The superplasticizer used was a polyacrylate, with a density of $1050 \mathrm{~kg} / \mathrm{m}^{3}$. The sand used has an average particle size of $439,9 \mu \mathrm{m}$ and a density of $2600 \mathrm{~kg} / \mathrm{m}^{3}$. The lime used in the compositions was a hydrated lime, with a purity of $90 \%$ and density of $2450 \mathrm{~kg} / \mathrm{m}^{3}$. The gypsum used is a traditional, with high fineness and density of $2740 \mathrm{~kg} / \mathrm{m}^{3}$. Finally, the fibers used are synthetic fibers of nylon, with a length of $6 \mathrm{~mm}$ and a density of $1380 \mathrm{~kg} / \mathrm{m}^{3}$. 


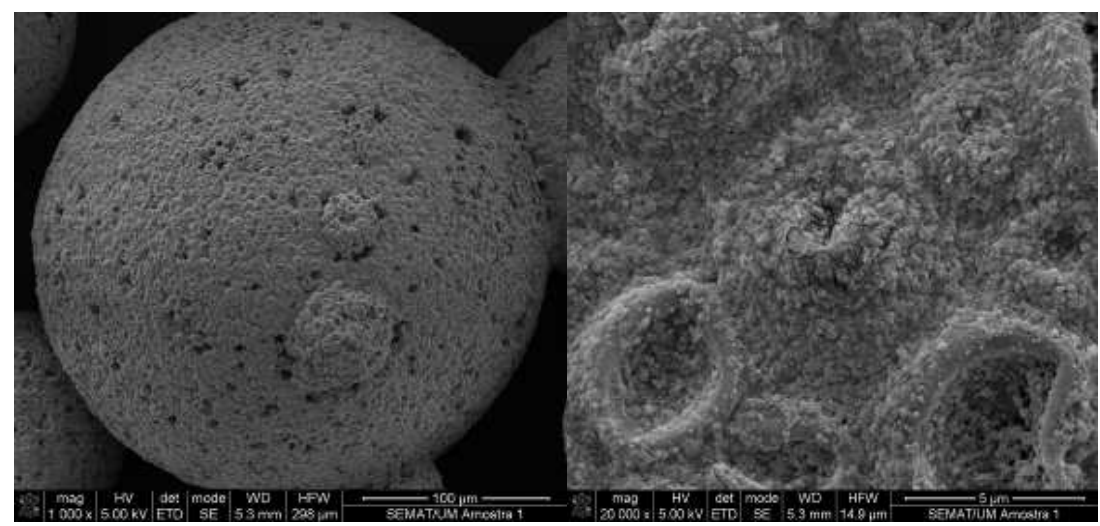

Fig. 1 Observation of polymer surface of the microcapsules A

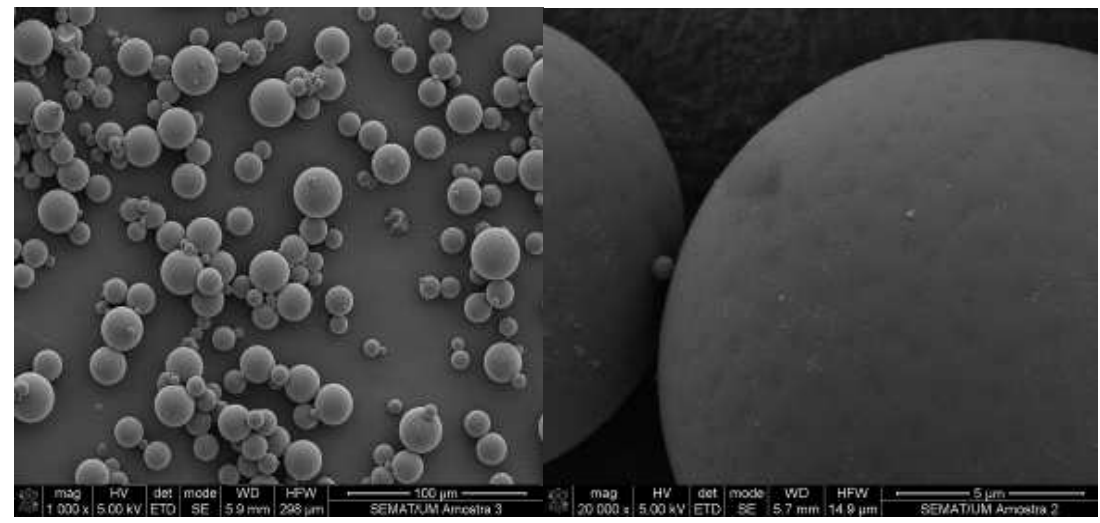

Fig. 2 Observation of polymer surface of the microcapsules B

Compositions and fabrication. In order to obtain the final composition an experimental campaign was considered, with the main goal of characterizing the produced compositions.

Table 1 Composition of mortars (PCM, water, superplasticizer and fibers as \% of total mass of solid particles; gypsum and sand as \% of binders mass)

\begin{tabular}{|l|l|l|l|l|l|l|l|}
\hline Compositions & Sand & PCM & Fibers & Gypsum & Superplasticizer & \multicolumn{2}{|l|}{ Water } \\
\cline { 7 - 9 } & & & & & & Microcap. A & Microcap. B \\
\hline L100G0 & 561.4 & 0.0 & 0.0 & 0.0 & 0.0 & 23.0 & 23.0 \\
\hline L100G0PCM20 & 561.4 & 20.0 & 0.0 & 0.0 & 1.0 & 29.0 & 25.0 \\
\hline L100G0PCM20F & 561.4 & 20.0 & 0.1 & 0.0 & 1.0 & 30.0 & 25.0 \\
\hline L90G10F & 561.4 & 0.0 & 0.1 & 10.0 & 0.0 & 23.5 & 23.5 \\
\hline L90G10PCM10F & 561.4 & 10.0 & 0.1 & 10.0 & 1.0 & 19.2 & 16.5 \\
\hline L90G10PCM20F & 561.4 & 20.0 & 0.1 & 10.0 & 1.0 & 31.0 & 25.6 \\
\hline L90G10PCM30F & 561.4 & 30.0 & 0.1 & 10.0 & 1.0 & 47.0 & 39.0 \\
\hline L80G20PCM20F & 561.4 & 20.0 & 0.1 & 20.0 & 1.0 & 31.0 & 26.0 \\
\hline L60G20PCM20F & 561.4 & 20.0 & 0.1 & 40.0 & 1.0 & 32.0 & 27.0 \\
\hline
\end{tabular}

Throughout this work, for the studied mortars the PCM content was varied between $0 \%, 10 \%, 20 \%$ e $30 \%$. In order to overcome some of the problems related with the mortar shrinkage and consequent cracking nylon fibers, superplasticizer and gypsum were incorporated. The studied compositions are presented in Table 1. Through its analysis it is possible to observe the existence of 9 different compositions with different contents of lime, gypsum and PCM. For every composition without PCM, it was decided not to include superplasticizer due to its dispersive effect, which caused a slight segregation of the mortar. The mixture procedure and specimens preparation was performed in accordance to the EN 1015-11 standard [2]. To evaluate the mechanical properties (compression and flexural strengths) of all the different compositions, 3 prismatic specimens with $40 \times 40 \times 160 \mathrm{~mm}^{3}$ 
were prepared. After their preparation all the specimens were stored during 7 days in polyethylene bags and subsequently placed in the laboratory at regular room temperature (about $22^{\circ} \mathrm{C}$ ) during 21 days.

\section{Test results and discussion}

Workability. The workability tests were performed with the main goal of verifying the adequacy of application of the developed mortars. The tests were performed based on the flow table method stated by the European standard EN 1015-3 [3]. The resulting values within the test were only considered when between 160-180 mm.

It was possible verify changes in the amount of water added to the mortar, according the incorporation of PCM microcapsules, taking into account the quantity and type of material added.

According to Fig. 3 it was possible to observe that the incorporation of $20 \%$ of the microcapsules A causes an increase in the amount of water of about $62 \%$. This situation can be explained by the reduced particle dimension of the used PCM and by the water absorption characteristics of the polymeric wall of the microcapsule. However, the incorporation of microcapsules B also causes an increase in the amount of water, but smaller, this being only about $12 \%$. This behavior can be explained by the use of capsules coated with a less rough and higher dimensions polymer.

The incorporation of fibers did not cause any change in the amount of water added to the mortar, however there was a slight reduction in the diameter obtained for the mortars doped with microcapsules A and B. The addition of $10 \%$ gypsum caused a slight increase in the amount of water. Being that, for the same mortar an increase of $20 \%$ of gypsum caused an increase of approximately $4 \%$ in the amount of added water.
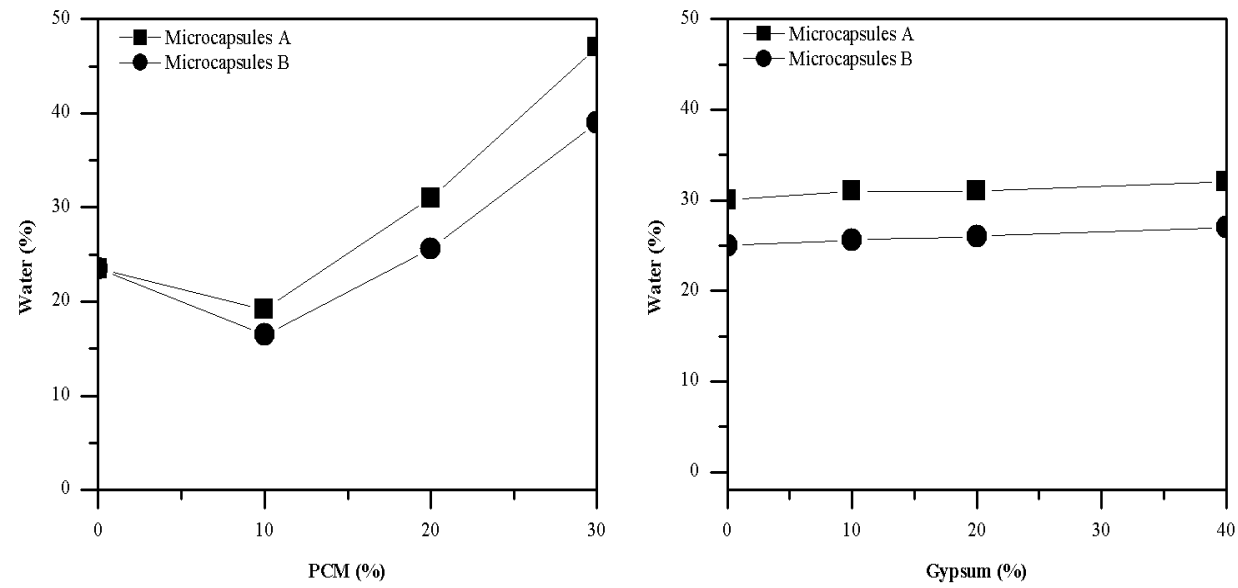

Fig. 3 Amount of water added to the mortar (in \% of total mass of solid particles)

Mechanical Behaviour. The flexural and compressive behavior was evaluated based in EN 1015-11. The specimens used for the flexural test were prismatic. The flexural tests were performed with force control at a speed of $10 \mathrm{~N} / \mathrm{s}$. Compression tests was realized through the application of a load on the specimen with resource to a metallic piece, rigid enough to make the vertical charge uniform. The specimens used for the test were the half parts resulting from the flexural test. The compression tests were performed with a force control at a speed of $50 \mathrm{~N} / \mathrm{s}$.

According to the results (Fig. 4) it is possible to observe a significant improvement in mechanical properties caused by the introduction of a greater amount of microcapsules A. However, the improvement of mechanical characteristics caused by the incorporation of microcapsules B is lower. The incorporation of $10 \%$ PCM leads to an increase in the value of flexural strength of about $380 \%$ and about $600 \%$ in compressive strength for the mortars doped with microcapsules A. Regarding the mortars with incorporation of microcapsules $\mathrm{B}$, the increase is about $85 \%$ in flexural strength and about $130 \%$ in compressive strength. These values were obtained comparing compositions with $10 \%$ of PCM with the composition without PCM. This increase in mechanical strengths is related to the 
increase of porosity caused by the introduction of higher water content. The increase in porosity benefits the carbonation of mortars, which was more evident in mortars doped with microcapsules A, since the water content present is higher in these mortars. However, it is possible to verify a decrease in the value of compression and flexural strength with a PCM content of $30 \%$ when compared to the $20 \%$ PCM composition. Therefore is possible to conclude that the optimal content of PCM in terms of mechanical properties corresponds to $20 \%$. Nonetheless, the value obtained for a PCM content of $30 \%$ is slightly higher or identical than the value presented by the mortar without PCM, which allows for the conclusion of the beneficial effect caused by the incorporation of PCM in mortars.
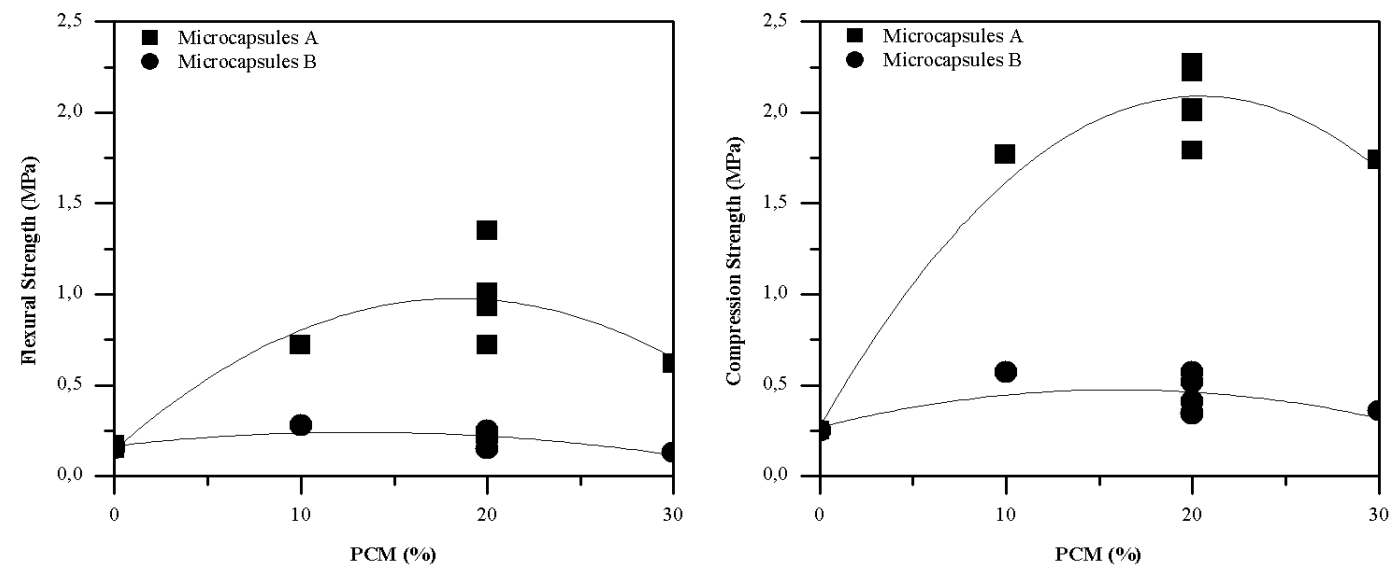

Fig. 4 Flexural and compressive behaviour

Shrinkage. The shrinkage study was performed for only 5 of the 9 compositions studied. Thus, it was possible to observe the influence of the presence of PCM microcapsules in the mortar, as well as the action caused by the introduction of nylon fibers and gypsum. The introduction of these materials had as main objective the reduction and control of shrinkage. For evaluating the shrinkage, a device capable of performing the measurement since the time of placing the mortar in the mold until the demolding, at 7 days, was developed. Previously to placing the mortar, the molds of the measuring device were prepared with an oil commonly used in formwork, aiming for the elimination of attrition in surfaces. After demoulding, it was possible to continue the monitoring of the shrinkage with another device. The device consists of a base for placing the triple mold with dimensions of $25 \times 25 \times 250 \mathrm{~mm}^{3}$ and six displacement transducers. Two displacement transducers were used for each specimen in order to enable the measurement of shrinkage on both sides further away from the specimen. The transducers are connected to a data acquisition system, where the values of shrinkage of mortars in time were registered. It was possible to make an evaluation of shrinkage since the fresh state, due to changes caused by the introduction of polymer capsules. The results allowed us to verify that there is an increase in the shrinkage with the incorporation of PCM microcapsules. However, the addition of gypsum and nylon fibers, results in a decrease in shrinkage in the first 24 hours of monitoring in mortars doped with both types of PCM microcapsules. The analysis of the results up to 7 days of age (Fig.5) in mortars with incorporation of the microcapsules A, allows the identification of different behaviors in different mortars. The introduction of $20 \%$ of microcapsules (L100G0PCM20), causes an increase in shrinkage of about 300\% compared to the reference mortar (L100G0). The addition of nylon fibers (L100G0PCM20F) causes a decrease in shrinkage to about 50\% compared with the mortar L100G0PCM20. With the addition of gypsum (L80G20PCMF and L60G40PCMF) is possible to observe a decrease in shrinkage. The addition of $40 \%$ gypsum allows a reduction in the shrinkage of about $60 \%$. The incorporation of $20 \%$ of microcapsules B (L100G0PCM20) causes an increase in shrinkage of about $20 \%$ compared to the reference mortar (L100G0). The incorporation of nylon fibers (L100G0PCM20F) allows for the verification of a decrease of about $30 \%$ compared with the mortar L100G0PCM20. Finally the incorporation of 40\% gypsum (L60G40PCMF) seems to cause a decrease in the value of shrinkage of about $60 \%$. The increase in shrinkage with the incorporation of PCM microcapsules is related to a greater amount of water used, while its reduction 
is caused by the inclusion of fibers, which are related to the prevention of dimension variations inside the mortar. Moreover, the reduction of shrinkage observed with the addition of gypsum, is connected to the expansion which occurs with its hydration. The incorporation of $20 \%$ of microcapsules $\mathrm{B}$, compared with the incorporation of $20 \%$ of microcapsules A, causes a decrease in shrinkage of about $70 \%$, which can be explained by the presence of lower water content in mortars doped with microcapsules B.

The thermal behavior of developed mortars was previously published [4].
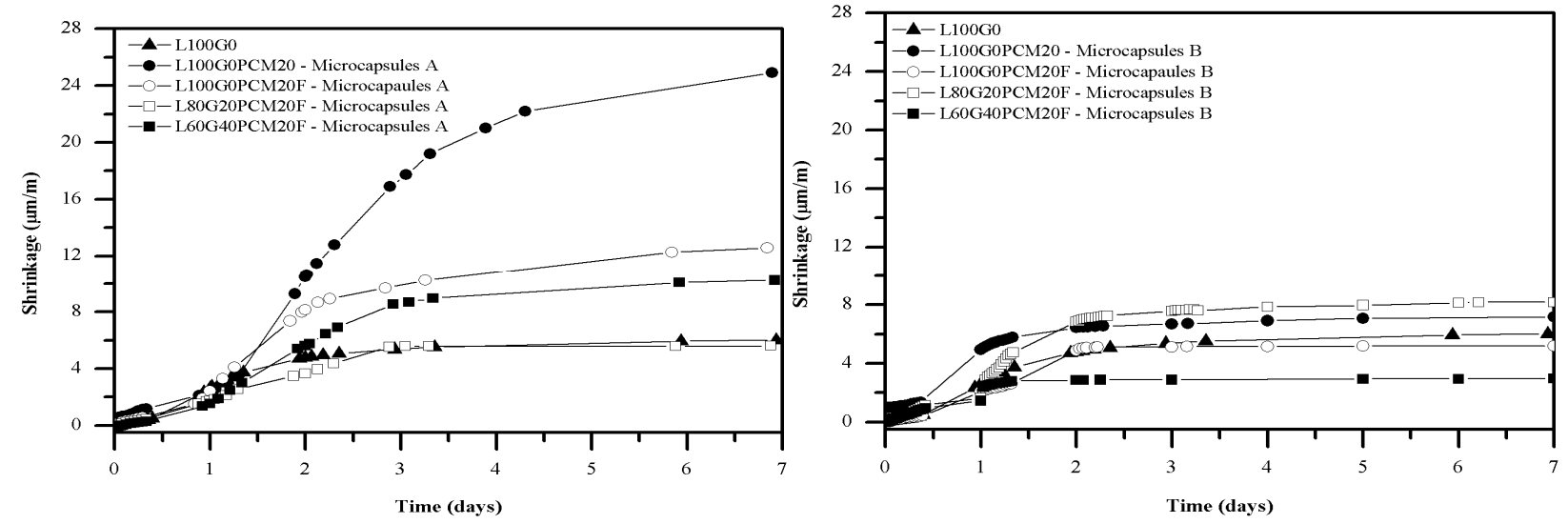

Fig. 5 Shrinkage test since moulding until 7 days in mortars with microcapsules A and B

\section{Conclusion}

Based on these results, it can be concluded that the use of PCM polymeric microcapsules in lime based mortars can be seen as a viable solution for applications in the construction industry. It is possible to achieve a viable compromise between their strength and aesthetic appearance. However, it was also verified that the use of different phase change materials microcapsules provides different characteristics in the different mortars, which is related to the type of polymer used for the construction of the wall of the microcapsules and also to their size.

The results obtained from tests of shrinkage concluded that the combined use of fiber and gypsum is a good solution to solve problems related to cracking caused by the incorporation of polymeric microcapsules. It was also observed that the use of microcapsules B provides values of shrinkage lower than those observed in mortars with microcapsules A. It was even possible to verify the existence of a clear rise of the water necessary to incorporate into the mortar with the increasing of PCM percentage, this with the aim of obtaining a suitable workability. The compression and flexural strengths measured in each performed test indicated a better performance for PCM microcapsules content between $15 \%$ and $20 \%$. This can be justified by the necessity of a greater amount of water in mortar with addition of $30 \%$ of PCM, causing a higher porosity, not compensated by the carbonation of mortars. It was also observed that the mortar with microcapsules A present an improved in mechanical behaviour compared to the mortars with microcapsules $\mathrm{B}$, which can be explained by the incorporation of a larger amount of water, which provided a greater porosity, facilitating the carbonation of the mortars.

The mortar with $60 \%$ of aerial lime and $40 \%$ of gypsum with incorporation of $20 \%$ of PCM microcapsules is more interesting for the both types of PCM microcapsules, since it showed an excellent compromise between mechanical strengths and shrinkage. 


\section{References}

[1] L. Cabeza, et al, Materials used as PCM in thermal energy storage in buildings: A Review, Renewable and Sustainable Energy Reviews. 15 (2011) 1675-1695.

[2] European Committee for Standardization (CEN). EN 1015-11. Methods of test for mortar for masonry - Part 11: Determination of flexural and compressive strength of hardened mortar (1999).

[3] European Committee for Standardization (CEN). EN 1015-3. Methods of test for mortar for masonry - Part 3: Determination of consistence of fresh mortar (by flow table) (2004).

[4] Sandra Cunha, et al, Thermal mortars: Contribution of the incorporation of PCM microcapsules, ASPIC 2012 - 7th Asian Symposium on Polymers in Concrete. (2012) 289-296. 
Progress in Polymers in Concrete

10.4028/www.scientific.net/AMR.687

Influence of Adding Encapsulated Phase Change Materials in Aerial Lime Based Mortars 10.4028/www.scientific.net/AMR.687.255 